\title{
$\mathbf{R}$
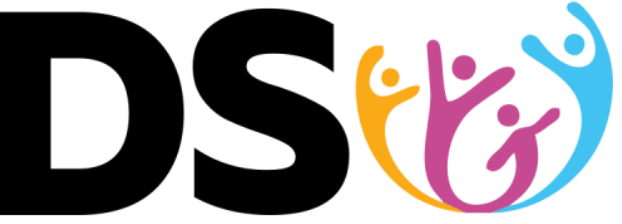

Vol. 27, n. 1, jan/jun, 2021

Revista Desenvolvimento Social

ISSN: 2179-6807 (online)

\section{A QUESTÃO DA REFORMA DA PREVIDÊNCIA BRASILEIRA NAS ELEIÇÕES DE 2018}

Augusto Baptista Bretas da Fonseca ${ }^{1}$

Recebido em: 27/01/2021

Aprovado em: 19/06/2021

Resumo: a reforma da previdência foi um importante ponto de atrito nas eleições presidenciáveis de 2018. Este trabalho busca evidenciar as principais narrativas em torno dela usadas pelas coalizões partidárias na disputa eleitoral. Para isso, utiliza-se os programas de governos liberados por todas as coligações e analisa-se sob a ótica dos trabalhos de formação de agenda e dos dilemas recentes do Estado de Bem-Estar Social. Mostrou-se que as principais narrativas centralizaram o debate em torno dos problemas econômicos em vez de sociais e podem se tornar um problema para o futuro da seguridade social brasileira.

Palavras-chave: Políticas públicas. Políticas sociais. Estado de Bem-Estar Social. Formação de agenda. Liberalização.

\section{THE ISSUE OF THE BRAZILIAN SOCIAL SECURITY REFORM IN THE 2018 ELECTIONS}

Abstract: the social security reform was an important issue of atritrion present in the presidential election of 2018. This article aims to show the foremost narratives used by the party coalitions involved in the elections about this issue. For this, I explore the governement programs liberated by all the coalitions, analyzing them with the help of agenda setting theroy as well as the new studies about the Welfare State. With this, I show that most narratives centered themselves around economical postulates instead of social ones. This can become a problem for the future of the Welfare State in Brazil.

Keywords: Public policies. Social policies. Welfare State. Agenda setting. Liberalization.

\section{LA CUESTIÓN DE LA REFORMA BRASILEÑA DE LA SEGURIDAD SOCIAL EN LAS ELECCIONES DE 2018}

Resumen: la reforma de la seguridad social fue una importante cuestión presente en las elecciones presidenciales de 2018. Este documento busca resaltar las principales narrativas empleadas por las coaliciones electorales. Para esto, usé los programas de gobierno difundidos por todas las coaliciones que se analizan desde la perspectiva del trabajo de construcción de agenda y los dilemas recientes del Estado de Bienestar Social.

1 Doutorando em Políticas Públicas, Estratégias e Desenvolvimento pela UFRJ. E-mail: abbretas@gmail.com. ORCID: 0000-0002-3253-087X. 
Se ha demostrado que las principales narrativas centralizaron el debate en torno a problemas económicos más que sociales y pueden convertirse en un problema para el futuro del Estado de Bienestar Social brasileño.

Palabras clave: Políticas públicas. Políticas sociales. Estado de Bienestar Social. Formación de agenda. Liberalización.

\section{INTRODUÇÃO}

A análise de política pública vai além de sua mera avaliação. Estudar o que o governo decide fazer ou não fazer não está atrelado apenas aos efeitos de suas ações, isto porque o que ele decide fazer é envolto de controvérsias e dilemas próprios.

Diversos estudos propuseram uma análise da formação de agenda, isto é, como problemas sociais se tornam problemas políticos e como se escolhem as soluções apropriadas para lidar com estes problemas. Trabalhos clássicos como o de Kingdom ([1984] 2014), Stone ([1988] 2012), Rochefort e Cobb (1994) e Wildasky ([1979] 2018) buscam entender os meios como agendas são formadas e assim impactando diretamente a produção das políticas públicas.

Trabalhos recentes têm salientado a importância do timing ${ }^{2}$ na política. Em grande parte um produto da nova teoria institucional, a variável "tempo" se tornou central para entender os processos políticos por meio de conceitos como os de conjunturas críticas (COLLIER E COLLIER, 2002), dependência da trajetória (PIERSON, 2000) e mudanças incrementais (STREECK e THELEN, 2005). O timing da política também foi trabalhado na análise de políticas públicas principalmente por meio do quadro analítico do equilíbrio pontuado (BAUMGATNER e JONES, 2009), ainda que o modelo de múltiplos fluxos (KINGDOM, 2014) tenha como proposta explorar a "chegada da hora de uma ideia" e assim usado o tempo como importante variável independente.

$2 \quad$ O conceito de timing se refere aos momentos oportunos para avançar agendas de mudanças. Aqui se inserem as ideias de conjunturas críticas e do equilíbrio pontuado que são momentos de desestabilização do status quo institucional onde novos atores e ideias conseguem impor mudanças importantes modificando as trajetórias políticas. Do outro lado, a dependência da trajetória faz a força oposta, explorando como a cristalização das instituições na sociedade impede que grandes transformações ocorram em demasia. Finalmente, a teoria das mudanças incrementais explora as pequenas mudanças que não chegam a mudar o status quo, mas que afetam, de diferentes maneiras, a trajetória política de uma regra. 
O trabalho proposto aqui visa explorar o tema do timing no ambiente das políticas sociais contemporâneas, mais especificamente da previdência brasileira. Não sendo um trabalho sobre uma reforma per se, o horizonte temporal do trabalho está inserido nas eleições presidenciais de 2018, na tentativa de compreender a ascensão do tema da reforma da previdência que ganhou contornos apocalípticos para o orçamento nacional em discussões políticas recentes e sua relação com fatores exógenos à dinâmica das políticas sociais.

Há grande discussão sobre a situação atual das políticas sociais e do Estado de Bem-Estar Social (EBES) contemporâneo.

De acordo com Kerstenetzky (2012) após os períodos de ouro e prata do EBES das décadas de 1950 a 1990, se iniciou o período contemporâneo que faz avançar uma nova agenda de políticas públicas que devem enfrentar novos dilemas.

A desindustrialização, a nova economia do conhecimento, a globalização, mudanças na estrutura da desigualdade, envelhecimento e menores taxas de fecundidade e, finalmente, mudanças na composição das famílias representam alguns dos novos dilemas que as políticas sociais devem enfrentar.

Além disso, o período pós 1990 representou, em quase todas as esferas da atuação estatal, o processo de liberalização (THELEN, 2014). A forma com que os diferentes países responderam aos novos dilemas e ao mesmo tempo reagiram à pressão da liberalização é a marca dos estudos recentes acerca dos EBES. Isto porque, além de exigir uma reforma institucional ampla, o processo de liberalização tem efeitos fortes sobre a proteção social seja por meio de mudanças nas próprias instituições de proteção social como também na dinâmica das políticas, por exemplo: no público-alvo das políticas ou nas formas e tamanho do financiamento destas políticas.

A reforma da previdência é certamente uma reação a estes fatores. Novas visões sobre a previdência surgem e impactam a agenda desta política social. Para o caso brasileiro, além dos fatores da dinâmica das políticas sociais, a crise econômica e política inciada $2014^{3}$ serve de gatilho para novas narrativas e enquadramentos para a questão.

3 Sobre este momento político do país eu recomendo os artigos de Serrano e Summa (2015), Boschi e Pinto (2019) e Prates et. al. (2019). A ideia central é de que o sucesso do manejo da crise financeira internacional de 2008 levou ao acirramento de duas coalizões, desenvolvimentista contra liberal/conservadora, onde, a partir de 2014, levou ao deterioramento das instituições políticas e das condições econômicas. 
Dessa forma, o questionamento é até que ponto a crise econômica e política afeta a formação de agenda de uma das políticas mais importantes do EBES.

O trabalho proposto é uma análise destas novas narrativas e enquadramentos e sua relação com as políticas sociais. Mais exatamente como os novos dilemas e o processo de liberalização do EBES são entendidos e trabalhados por formadores de agenda para que eles possam avançar a temática da reforma da previdência.

A formação da agenda de políticas sociais já foi explorada por Banting e Myles (2016), com um foco nas políticas de redistribuição de renda. Para estes autores, a formação da agenda é uma função da relação entre ideias, interesses organizados e o processo eleitoral/partidário. Neste trabalho, esses autores (BANTING e MYLES, 2016) buscaram mostrar os diferentes enquadramentos possíveis da questão estudada com ajuda do que se sabe empiricamente sobre a estrutura da nova desigualdade. Assim, a questão da desigualdade ganhou enquadramentos contemporâneos como os do discurso da anti-pobreza, do enquadramento dos $99 \%$ contra os $1 \%$ e da questão da classe média.

Os novos enquadramentos e a possibilidade de pensar novas políticas e instituições criam uma arena onde ocorrem batalhas entre ideias, grupos de interesses e partidos políticos em que cada um quer controlar os rumos da trajetória política. Mais do que isso, os autores demonstram a importância das alianças, principalmente na possibilidade de cooptação da classe média, como medida de força importante para o sucesso eleitoral e de política pública das próprias narrativas. Isto porque, mesmo em teorias construtivistas, as ideias sempre precisam de vetores para sua utilização e reprodução.

Cada um dos enquadramentos trabalhados por estes autores possui uma narrativa que constrói um arcabouço de problemas e soluções. Nesta perspectiva, o enquadramento é a ação de domesticação de um problema. Identifica-se uma questão social que possa se tornar um problema político e define-se os seus limites. Dessa maneira, ocorre um acoplamento de uma solução necessária, defendida por quem enquadrou o problema. Assim, problemas e soluções ganham "donos" políticos.

O trabalho proposto visa fazer o mesmo percurso que estes autores fizeram, analisando os enquadramentos da política de uma nova previdência. O que se deseja mostrar são estas narrativas com capacidade de definição dos problemas/soluções. $\mathrm{Na}$ 
medida do possível, pretende-se mostrar a relação da narrativa com os problemas contemporâneos do EBES de um lado e a grave crise econômica e política do Brasil de outro.

A principal hipótese é de que o tema da reforma da previdência ganhou força com o prosseguimento da crise econômica brasileira (BOSCHI e PINTO, 2019) e, por isso, os enquadramentos vão além dos dilemas clássicos do EBES contemporâneo. É bem possível que os problemas previdenciários evidenciados pela coalizão pró-reforma já eram de conhecimento técnico, o que quer dizer que outros mecanismos estão fazendo com que o tema tenha adquirido relevância no período analisado. Isso significa que fatores circunstanciais estão pautando uma agenda de políticas que lidam com a vida das pessoas em horizontes temporais maiores do que estes condicionantes.

A análise partirá de um ponto de vista qualitativo, não sendo possível precisar o grau de força que a crise econômica tem na agenda previdenciária. O que se espera mostrar é uma relação entre crise político-econômica e a mudança nas políticas sociais, onde a crise desempenha um papel importante a mais sobre os outros dilemas contemporâneos do EBES.

\section{TRANSFORMAÇÕES NO ESTADO DE BEM-ESTAR SOCIAL}

O Estado de Bem-Estar Social e suas instituições estão certamente mudando. Seu aparato institucional de proteção social tem sido confrontado por novos dilemas, novos atores e novas ideias que levam inevitavelmente a novos arranjos institucionais.

Na base das mudanças no EBES está a própria mudança no conteúdo e na forma da desigualdade no período contemporâneo, e que foi trabalhada por artigos como o de Banting e Myles (2016) e exposta no livro de Piketty (2014). Para Piketty (2014) o cerne da desigualdade está sempre atrelado a possibilidade de usufruir de ganhos sobre o capital. Como a má distribuição do capital é mais acentuada que a do trabalho, ainda que o surgimento de uma classe média patrimonial seja a marca do pós-segunda guerra, aqueles que detém capital e conseguem retirar ganhos de suas propriedades se distanciam na escala da renda nas sociedades.

Historicamente a desigualdade tem sido uma constante nas sociedades pósindustriais estudadas por Piketty. O grande marco disruptivo ocorreu nas duas grandes 
guerras com eventos como a crise de 1929, a falência de diversos bancos, a destruição causada pela guerra e uma série de políticas públicas adotadas em relação ao fisco, ao rentismo e à proteção social (PIKETTY, 2014:253).

De fato, o momento do pós-guerra quando foram arquitetadas as principais instituições que são a marca do EBES foi a idade de ouro do EBES. No entanto, é importante ressaltar que o EBES não surgiu sem sua própria resistência. De fato, para Kerstenetzky (2012) o EBES convive com o cenário de crise anunciada desde a década de 1970.

De acordo com Piketty (2014) a desigualdade total teve sua rota descendente iniciada na década de 1940 e interrompida na década de 1980 quando ela voltou a apresentar uma característica ascendente (aumento da desigualdade).

Uma marca deste novo período da desigualdade está na ideia do $1 \%$. Este conceito engloba uma parcela da população que tem se distanciado cada vez mais do restante da população e abocanha valores cada vez maiores da renda nacional total, um fenômeno compartilhado por vários países. Além de ganhos sem precedente em capital, houve um aumento da desigualdade nos ganhos por trabalho com o surgimento de supersalários que premiam altos executivos empresariais.

As novas dinâmicas do trabalho no mundo contemporâneo não têm efeitos só sobre a desigualdade como também são um dos principais dilemas do EBES. A estrutura do mercado de trabalho tem sofrido mudanças constantes em três frentes conectadas entre si: 1) a diminuição da importância da manufatura e ascensão do setor de serviços, que cada vez mais se torna o principal contratante de trabalho nas sociedades, bem como a mudança na forma e no conteúdo dos contratos de trabalho; 2) a mudança nas estruturas familiares e o aumento da participação feminina no trabalho; 3) e o surgimento da inteligência artificial e robôs capazes de prover não apenas trabalho em fábricas como também serviços do dia a dia.

Todas estas mudanças vão ao encontro do que Bonoli (2006) chama de novos riscos sociais. Para este autor, as mudanças não ocorrem apenas no mercado de trabalho e na divisão setorial da economia, elas também surgem de novos desafios na família e no cuidado. Há uma maior dificuldade de conciliar trabalho e vida familiar por razões como: um aumento do número de pais solteiros, uma maior dificuldade em conciliar cuidados de entes delicados como crianças e idosos, uma maior dificuldade de integrar 
trabalhadores com habilidades pouco produtivas ou obsoletas, uma presença de contratos de trabalho sem período integral e progressão de carreira especificada. Assim, há uma presença de instituições que foram criadas para lidar com dilemas bem diferentes dos apresentados em sociedades pós-industriais (BONOLI, 2006:6-8).

Todas estas mudanças certamente representam problemas que devem ser combatidos por meio de novas políticas públicas. No entanto, este processo esbarra em questões atuais do EBES. Afinal o que fazer com as instituições existentes de proteção social, previdência, educação e saúde?

Tanto para Bonoli (2006) quanto para Thelen (2014) e Kerstenetzky (2012), os diferentes países com regimes de bem-estar social responderam a estes dilemas de formas bem diferenciadas.

Os novos dilemas e os novos riscos sociais colocam na arena política novos interesses organizados. Trabalhadores do setor de serviços anseiam por instituições diferentes daquelas pensadas para proteger os trabalhadores do setor da manufatura. Da mesma forma, as instituições que resolviam os problemas familiares de trabalhadores masculinos não estão adequadas para responder aos dilemas das novas famílias, como as monoparentais.

Não apenas as instituições passam a ser contestadas, como há uma nova reconfiguração da economia política com novos interesses sendo organizados e disputando a trajetória institucional. Finalmente, esta disputa ocorre em um arranjo institucional já existente que enquadra as ações possíveis dos atores e da disputa política.

Para Banting e Myles (2016) estas novas configurações têm pela frente o desafio de enquadrar a nova política social. Um dos grandes desafios dos novos interesses organizados, seja de empresários (ricos) ou trabalhadores (pobres), é de se aproximar de uma classe média para aumentar o poder de definição das políticas, principalmente por meio de partidos políticos e vitórias eleitorais.

Estes autores definem um enquadramento político como um modelo simplificado de descrição (o que está acontecendo e porque está acontecendo, incluindo narrativas e relações causais) e normatividade (a moralidade do que está acontecendo, se é bom ou ruim, e o que pode e deve ser feito) (BANTING E MYLES, 2016:515-516). 
Assim, os enquadramentos são uma forma de construção de narrativas com o propósito de angariar apoio para problemas e alternativas específicas, especialmente em questões que perpassam a sociedade inteira como a maioria das políticas sociais. Esta teoria se torna interessante pois, além de fornecer limites para o que podemos pensar como problemas e soluções para os novos riscos sociais, os enquadramentos servem também para conquistar públicos para as diversas direções que podem tomar o EBES contemporâneo.

Todos os autores trabalhados aqui concordam que o EBES está mudando. Porém, sua transformação não é linear e depende de diversos fatores. De fato, diferentes países têm adotados diferentes políticas e trajetórias que dependem de fatores internos a eles, como a organização dos interesses dentro de suas sociedades e o manejo das antigas instituições de proteção social que são alvo das mudanças e que, no entanto, também mostram resiliência às tentativas de alteração.

Esta discussão foi muito influenciada pelos três tipos ideais de EBES propostos por Esping-Andersen (1993) que os separou em três regimes diferentes: liberal; conservador; e social-democrata.

Como coloca este autor, diferentes regimes de bem-estar surgiram após trajetórias bem diferentes de percursos históricos, institucionalidades, economias políticas, e objetivos e resultados alcançados. Da mesma forma, esta diversidade projeta diferentes tendências e resistências. Para Bonoli (2006) os novos riscos sociais ocorrem de forma muito diferenciada entre os países desenvolvidos, ora surgindo com mais intensidade em uns, ora mais precocemente em outros.

Desse modo, países foram agrupados em conjuntos que pudessem capturar as principais características deles acerca da proteção social e do bem-estar. EspingAndersen (1993) utilizou três eixos para fazer sua caracterização: o conflito público x privado; a desmercantilização para a realização do bem-estar; e a estratificação social promovida pelas instituições de bem-estar.

Assim, o regime liberal, exemplificado pelos casos de Inglaterra e EUA, é caracterizado por uma provisão privada alta, baixo grau de desmercantilização e dualização do bem-estar. O regime conservador, que tem como principal país a Alemanha, é caracterizado pela forte presença pública na provisão de bem-estar, grau intermediário de desmercantilização e segmentação ocupacional do bem-estar. 
Finalmente o regime social-democrata, exemplificado pelos países escandinavos, apresenta elevada provisão pública, elevada desmercantilização e universalismo das políticas sociais (KERSTENETZKY, 2012:96-98).

Para a autora Kathleen Thelen (2014) estes diferentes regimes já apresentam trajetórias próprias quanto à capacidade de lidar com as mudanças estruturais econômicas e de proteção social. A divergência nas trajetórias já fez possível uma tipologia das respostas aos desafios e dilemas do EBES contemporâneo. Assim como há três tipos principais de regime de bem-estar, há também três tipos principais de mudança no EBES contemporâneo.

Para esta autora as mudanças podem ocorrer tanto quantitativamente no âmbito da cobertura da proteção social quanto qualitativamente na forma da cobertura da proteção social.

O caso extremo de mudança nos dois eixos é o da desregulação que ocorre principalmente nos regimes liberais de bem-estar. Neste caso há um ataque frontal e direto às instituições de proteção social em que a cobertura é reduzida e o conteúdo da proteção social é afrouxado dando maior destaque aos mecanismos de mercado para todas as questões de bem-estar, como, por exemplo, a distribuição de renda ou a arbitragem entre empregadores e empregados.

Os casos de mudança apenas no eixo da cobertura foram denominados de dualização. Neste caso, há uma tentativa de resguardar as instituições mantendo uma presença forte do Estado na proteção social. Entretanto, por motivos diversos relacionados aos novos riscos sociais esta proteção acaba se reduzindo. O processo acaba levando a um sistema de confronto entre insiders contra outsiders.

Para Thelen (2014) o caso mais bem-sucedido de resistência, ocorrido principalmente nos países nórdicos, foi o da mudança no eixo qualitativo chamado de flexibilização inserida. Nesta trajetória, os EBES não abandonam o universalismo como valor, mas se adaptam aos novos riscos sociais, moldando as instituições para que elas sejam capazes de resolver os novos dilemas. Assim, para a autora, a conservação de instituições que foram criadas para lidar com dilemas e desafios de 70 anos atrás talvez não sejam os melhores meios para se enfrentar os dilemas contemporâneos. De fato, o processo de dualização é descrito como um recrudescimento da desigualdade. 
Contudo, é importante frisar que a trajetória institucional não segue um caminho funcionalista de escolha racional. As diferentes trajetórias existem pelos diferentes fatores que afetam os países e os regimes. Por outro lado, é importante não cristalizar as trajetórias por completo como se as sociedades não pudessem levar seus países para outros caminhos.

É neste sentido que é importante explorar os enquadramentos, isto é, os discursos dos formadores de opinião, sejam midiáticos, técnicos ou acadêmicos e a aceitação geral dos fatos e argumentos apresentados pelos diferentes lados. Seria de fato ingênuo acreditar que ninguém argumentará pela desregulação ou pela dualização pois ambas respostas podem trazer benefícios específicos a diferentes grupos.

De fato, para a própria autora (THELEN, 2014) a autonomia do Estado e as capacidades estatais são variáveis importantes para explicar grande parte da trajetória de resposta aos novos riscos sociais.

\section{BUSCANDO APOIO: RECURSOS DE PODER E ESTRATÉGIAS PARA FORMAR AGENDAS}

Para Banting e Myles (2016) os enquadramentos são importantes pois sinalizam a determinação exata do problema (e.g. qual o problema da previdência) e a solução adequada para resolver este problema (e.g. devemos fazer $\mathrm{X}$ para resolver este problema). Contudo, em democracias, os enquadramentos servem também para conquistar apoio. Assim, eles fazem parte não só do embate das ideias, mas tangenciam também o próprio embate do poder concreto e da capacidade de determinar e controlar a trajetória instrucional de uma sociedade.

Esta ideia está em concordância com um dos principais modelos de explicação do surgimento de diferentes regimes de bem-estar, a teoria dos recursos de poder ${ }^{4}$.

A teoria dos recursos de poder coloca, em termos simplificados, que há uma relação entre o grau de mobilização dos trabalhadores, principalmente em sindicatos com capilaridade em partidos, e o tamanho do EBES. Quanto mais mobilizados forem os trabalhadores, e maior sua capacidade de pautar a agenda política elegendo políticos simpáticos a suas ideias, maior será a cobertura de proteção social e mais ela estará em

4 O principal defensor dessa teoria é o próprio autor Esping-Andersen (1993). 
sintonia com os anseios destes trabalhadores. Dessa forma, a teoria reduz o surgimento de diferentes regimes de bem-estar às capacidades dos partidos políticos (Social Democratas em países escandinavos e Democratas Cristãos em países conservadores) de cada país em pautar a agenda do bem-estar.

Autores como Thelen (2014) e Rothstein et. al. (2012) tem contra-argumentado que esta teoria, apesar de seus méritos, não compreende a realidade em sua totalidade. $\mathrm{Na}$ verdade, a teoria dos recursos de poder tem deixado de fora o Estado e seu protagonismo institucional.

Em Thelen (2014), a teoria dos recursos de poder é incapaz de responder questões sobre as mudanças recentes, principalmente com a desagregação dos interesses dos trabalhadores. A ascensão do setor de serviços, especialmente com novos modelos de contratos como "part time jobs" e serviços "on demand", complicou a arena dos embates acerca do futuro das instituições de proteção social na medida em que criou uma série de trabalhadores que enfrentam novos dilemas e tem outras aspirações. Além disso, o processo de dualização é visto como um retrocesso na medida em que cria atrito entre trabalhadores da manufatura e aqueles dos novos serviços. Por isso, o Estado precisa ter capacidade e autonomia para enfrentar os interesses do setor manufatureiro para revisar suas instituições ao mesmo tempo em que garante elevados níveis de proteção social a sua população.

Rothstein et. al. (2012) ampliam a questão ao trazer o conceito de Qualidade dos Governos. Os autores se perguntam porque os trabalhadores deveriam recorrer ao Estado para prover a proteção social onde outros modelos podem existir. Para estes autores, esta discussão é especialmente importante quando a análise se centrar em países em desenvolvimento porque frequentemente a discussão estará centrada na qualidade ruim do serviço público e nos casos de corrupção. Dessa maneira, a sustentação do EBES tem mais um obstáculo: o enquadramento da corrupção e da baixa qualidade do governo.

O caso de Rothstein et. al. (2012) é interessante pois revela mais um problema que pode se acoplar à discussão do bem-estar. Isto porque formações de agenda raramente seguem processos lineares e convergentes. Atores disputando agendas devem utilizar táticas e estratégias para que eles possam enquadrar os problemas a suas maneiras e para promover suas soluções e assim controlar a trajetória institucional das 
sociedades. O uso do termo corrupção e a exposição da fragilidade do Estado se torna um argumento para conquistar apoio a determinados projetos específicos, principalmente de desregulação do EBES.

O Estado tem a primazia de fazer as políticas públicas. No entanto, sua capacidade de resguardar certos interesses depende de sua autonomia perante interesses externos. Os conceitos de capacidades estatais e autonomia do Estado ${ }^{5}$ são sempre conceitos relacionais e devem ser entendidos caso a caso.

Atores que queiram promover suas visões de mundo e assim influenciar a produção de políticas públicas devem primeiro formar agendas em torno de problemas e soluções. Grande parte dos autores que estudam agendas concordam que é impossível saber a priori quais são os problemas políticos enfrentados por uma sociedade. Atores devem construir narrativas e discursos além de utilizar táticas e estratégias para conseguir apoio para seus projetos.

Autores clássicos têm estudado a formação de agenda, porém todos partem do pressuposto organizado por Birkland (2007:77) de que a formação de agenda não ocorre no vácuo e que a ascensão de uma questão depende da própria questão, dos atores envolvidos, dos arranjos institucionais presentes e, ainda, de fatores sociais e políticos aleatórios que podem não ser replicados ou previstos.

Tanto para Kingdom (2014) quanto para Rochefort e Cobb (1994) questões na sociedade passam por diferentes estágios até se tornarem problemas políticos. Por exemplo, Kingdom (0214) utiliza o conceito de fluxos para explicar como as questões da sociedade são trabalhadas. Cada fluxo apresenta atores chaves e variáveis importantes que podem ser destacadas para a formação de agenda. Já Rochefort e Cobb (1994) afirmam que há uma multiplicidade de agendas, desde uma sistêmica até uma institucional, e que em cada uma dessas agendas novos pontos de veto surgem assim como o caso de diferentes atores se tornarem mais coadjuvantes, perdendo sua capacidade de influência, e outros ganhando poder.

O policymaker sempre tem a palavra final, porém sua própria visão do problema é um constructo. Eles geralmente demandam informações de outros atores e sondam a receptividade de ideias e soluções. Para Kingdom (2014) alguns fatores podem

5 Para uma discussão um pouco mais aprofundada ver Sckopol (1985), por exemplo. 
influenciar a dinâmica da formação de agenda que incluem: o surgimento de novos índices e informações relacionadas ao problema em si; desastres e eventos imprevisíveis; eleições de partidos que estavam na oposição e/ou que apresentam novas visões sobre o problema pesquisado; ascensão e declínio de grupos de interesse e coalizões.

Já os autores Rochefort e Cobb (1994) alertam que a agenda política depende de questões institucionais de transparência, participação e deliberação. Muitas vezes, discursos técnicos tentam se apropriar de questões oferecendo soluções específicas legitimadas por meio da tecnicidade de seus argumentos blindando a discussão política de organizações da sociedade civil, assim sendo mais um obstáculo para os recursos de poder de trabalhadores. Dessa forma, uma estratégia dos grupos de interesse é situar o debate em campos técnicos bloqueando a entrada de novos participantes ao afirmar que estes desconhecem o tema, ou usando o conceito de politização do tema como algo ruim.

A autora construtivista Deborah Stone (2012) dá ênfase na construção das narrativas e suas táticas implícitas e explícitas de convencimento. Por exemplo, discursos que apelam às necessidades são mais convincentes do que aqueles que apelam às vontades. Narrativas têm como característica o uso de símbolos, números, relações causais e criam heróis e vilões usando metáforas e outras figuras de linguagem. Para esta autora, numa comunidade política os tomadores de decisão não devem apenas apelar para a razão das pessoas, mas também para suas emoções e seus sentimentos, reforçando sistemas de lealdade e confiança.

Alguns autores contemporâneos tentam sintetizar a discussão da formação de agenda e suas estratégias. Para Zahariadis (2016) a formação de agenda depende dos "4Ps": Poder e a capacidade de alguns atores de definirem quais problemas serão levados a sério; Percepção onde tomadores de decisão fazem o público conhecer o problema de certas formas; Potência onde a intensidade das ações e suas consequências são armas dos policymakers; e Proximidade pois quanto mais próximo é um problema dos stakeholders (os interessados pela política) maiores são as chances deles concordarem com linhas de ações específicas.

Finalmente, para Zittoun (2014) a formação de agenda é uma questão de policies statements. Formadores de opinião devem delimitar exatamente o problema a ser 
enfrentado acoplando soluções a ele no momento da delimitação, isto porque problemas não tem donos (é o caso dos Wild Problems ou Wicked Problems), porém soluções sim. Estes atores devem criar grupos de vítimas e de beneficiários e devem explorar as contradições entre estes grupos. Assim, a política pública é reduzida a uma questão de vencedores e perdedores (coalizões discursivas) e a tentativa de mudança desse status quo.

\section{O REGIME CONTEMPORÂNEO DA PREVIDÊNCIA: TRAJETÓRIA E TIMING PARA MUDANÇA}

Como então as coalizões de interesse na previdência utilizaram estas estratégias e tentaram formar a agenda política da questão?

O regime contemporâneo da previdência se inicia na promulgação da constituição federal de 1988. Neste marco foi criado o conceito de Seguridade Social que, posteriormente em 1990, seria gerido pelo INSS. As duas grandes leis criadas para reger a previdência social foram as leis 8.212 e 8.213. O período do final da década de 1980 e início da década de 1990 viu a consolidação de uma previdência que não fazia distinção entre trabalhadores urbanos e rurais, com um piso mínimo, avanços no sentido da universalização e na ampliação da cobertura, ainda que servidores públicos ficaram com regime diferenciado de previdência. Assim, a previdência ficou marcada pela existência do Regime Geral de Previdência Social (RGPS) e os regimes diferenciados.

Para os autores Marques et. al. (2008) toda a década de 1990 foi caracterizada pelo embate entre uma visão inclusiva e ampliada de previdência social e um projeto neoliberal marcado pelo fim da solidariedade social e o estabelecimento de um sistema capitalizado, financista e individualizado.

A trajetória previdenciária mostra que, desde a promulgação da constituição de 1988, a previdência no Brasil jamais esteve completamente blindada de embates sobre suas instituições principais. De fato, muitas emendas constitucionais foram aprovadas como pequenas e médias reformas, sempre no sentido de diminuir a cobertura da previdência social num processo de adição de camadas institucionais. 
Destacam-se as emendas constitucionais EC 20/98 e EC 41/03 como reformas importantes, e as EC 3/93, EC 47/05, EC 70/12 e a EC 88/15 como pequenas alterações institucionais que ampliaram o processo de perda da cobertura previdenciária.

Marques et. al. (2008) mostram que fatores externos à previdência foram usados como artifícios para promover estas mudanças em direção a uma menor cobertura, isto é, a uma desregulação da previdência. Por exemplo, uma desvinculação da receita proposta no Plano Real ( $20 \%$ do orçamento da seguridade social podia ser alocado livremente) somado a um fraco desempenho da economia foram usados como argumentos centrais para a reforma da EC/20 de 1998.

Da mesma forma, a emenda constitucional de 2003 utilizava comparações equivocadas entre benefícios extremamente altos generalizando-os para promover pontos específicos de mudança (MARQUES et. al, 2008:213-214). Neste ano também, o governo do PT começava em meio a muita desconfiança, principalmente pelo mercado, o que fez o partido passar por cima das conviç̧ões de sua própria base eleitoral.

Em 2014, ano eleitoral com vitória de Dilma ainda pelo PT, o país já dava sinais de entrar em uma prolongada crise econômica e política que posteriormente ficou marcada principalmente pelo impeachment da presidenta em 2016 (BOSCHI e PINTO, 2019). Especificamente no ano de 2014 a situação ainda não era de crise. O desemprego no ano foi o menor desde o início da série da PNAD contínua do IBGE e o PIB brasileiro ainda não havia começado a decrescer. A situação econômica deteriorou rapidamente nos anos subsequentes de 2015 e 2016 registrando queda média de 3,5\% no PIB, de acordo com as contas do IBGE.

É importante mencionar que, assim como em 1998 e 2003, o orçamento contou com significativas mudanças no sentido de arrocho orçamentário. O governo Temer deixou como principal legado o Novo Regime Fiscal, conhecido também como a PEC do Teto de Gastos (EC95/2016). Esta contenção de gastos levou muitos partidos a colocarem em seus programas reformas fiscais amplas, incluindo uma reforma da previdência que desvincularia receitas e aumentaria a discricionariedade orçamentária do executivo.

De acordo com o resumo da PNAD contínua (IBGE, 2019) os resultados do mercado de trabalho mostram o aumento da precarização do trabalho que pode ajudar a ampliar os argumentos pela desregulação e/ou pela dualização da proteção social. 
O resumo desde período de 5 anos mostra claramente dados que sugerem uma precarização do trabalho e um avanço para o setor de serviços, principalmente para o setor informal. O número total de pessoas desocupadas subiu de 6 milhões de pessoas em 2014 para quase 13 milhões em 2018. Entre as pessoas ocupadas, o número de empregados diminuiu enquanto o número de empregadores e trabalhadores por conta própria aumentou. Da mesma forma diminuiu a quantidade de pessoas trabalhando com carteira assinada no setor privado. Setorialmente, os setores que mostraram mais retração foram a indústria, a construção e a agricultura, todos com um decréscimo de $10 \%$ no número de trabalhadores no período $2014 / 18$. Do outro lado, serviços como transporte, alojamento e alimentação (todos os setores que contam com importantes aplicativos de economia compartilhada) mostraram elevada tendência de crescimento além do setor de "outros serviços".

\begin{tabular}{r|ccccc} 
& 2014 & 2015 & 2016 & 2017 & 2018 \\
\hline Taxa de desocupação & 6,8 & 8,5 & 11,5 & 12,7 & 12,3 \\
\hline Taxa de pessoas no & 73 & 72,3 & 71,9 & 71,6 & 71,3 \\
setor privado & & & & 18,7 \\
\hline Taxa de pessoas no & 17,8 & 18 & 18,1 & & \\
setor público & & & & & \\
\hline Taxa de pessoas & 4,9 & 5,3 & 5,3 & & \\
subocupadas & & & & 3,8 & \\
\hline Taxa de pessoas & 1,5 & 1,9 & 3,1 & & \\
\hline desalentadas & & & & & \\
\hline
\end{tabular}

Quadro 1: Taxas representativas do momento trabalhista no Brasil pré-eleição 2018

Fonte: IBGE, 2019.

Destaca-se também o aumento do percentual de pessoas empregadas no setor público mostrando a resiliência trabalhista neste setor. Não apenas a desocupação como 
desemprego tem avançado como também a precarização dos contratos com aumento de pessoas em estado de sub-ocupação por insuficiência de horas trabalhadas.

Todos estes dados impactam a percepção das pessoas sobre a previdência. Utilizando o modelo de Zahariadis (2016) podemos dizer que a proximidade e a potência dos problemas previdenciários aumentaram consideravelmente visto que muitos trabalhadores não tem mais esperança de participar do RGPS, tampouco de usufruir dos direitos trabalhistas. Dessa forma, a eleição colocou frente a frente coalizões distintas de tratamento da questão previdenciária onde os grupos tentaram identificar inimigos, construir narrativas e evidenciar o problema central e a solução específica.

\section{ELEIÇÃO DE 2018 E COALIZÕES PREVIDENCIÁRIAS}

As eleições presidenciais de 2018 contaram com dois turnos. Foram 13 candidatos, 8 coligações e 7 debates. Todas as coligações disponibilizam programas de propostas de governo que com o programa do partido NOVO (que não se coligou com nenhum outro partido) contabilizaram 9 programas ao todo. Entretanto, estes programas variam enormemente em conteúdo e forma. Eles vão desde programas detalhados, como por exemplo o de 221 páginas dos candidatos Guilherme Boulos e Sonia Guajajara (PSOL), até modelos simples como o programa de metas em apenas 15 páginas dos candidatos Álvaro Dias e Paulo Rabelo (Podemos e PSC).

O período eleitoral é o momento privilegiado em democracias para a apresentação dos planos de governo que escolherão quais problemas sociais transformar em problemas políticos e também pontuar que soluções são as mais apropriadas para lidar com estes problemas.

A previdência apareceu fortemente nos programas dos governos onde todos eles contaram com, pelo menos, algumas frases sobre ela. Podem ser observados pontos comuns e dissidentes entres os programas.

Os dois programas mais diferentes ficaram por conta das coligações "O povo feliz de novo" do PT e "Vamos mudar sem medo" do PSOL. Alguns comentários serão devotados separando estes dois programas. Os outros 7 programas defendem uma mudança na previdência, ainda que apresentem diferenças entre eles. O modelo de capitalização aparece claramente em apenas 2 deles: "Mudança de verdade" e "Brasil 
acima de tudo, Deus acima de todos". Além disso, um modelo misto é proposto pelas coligações "Unidos para transformar o país" e "Brasil soberano".

De certa forma, pode-se dizer que os partidos obedeceram a suas posições no espectro contínuo de direita-esquerda, onde as coligações mais à direita defenderam abertamente a capitalização e os partidos mais à esquerda defenderam a manutenção da previdência social e da solidariedade. A exceção fica pelas coligações do PDT/Avante e Rede/PV que se colocaram como centro-esquerda, ainda que abertamente tenham defendido um modelo semi-capitalizado de previdência com algum abandono do sistema de solidariedade vigente.

Apenas a coligação "O povo feliz de novo" defendeu a manutenção estrita da previdência. Utilizando o modelo das mudanças recentes de Thelen (2014) podemos dizer que a coligação do PT está mais próxima da dualização, onde os mecanismos institucionais são mantidos sem questionar a capacidade institucional de englobar os novos dilemas que surgem de forma exógena na economia, principalmente no mercado de trabalho.

Como colocado pela autora, o que acaba ocorrendo é uma diminuição da cobertura por motivos de defasagem institucional, além de um acirramento entre insiders e outsiders. Para esta coligação, a resposta aos problemas que foram atrelados à previdência, principalmente em sua questão fiscal, deve ser que eles sejam resolvidos no ambiente macroeconômico amplo com a retomada da criação de empregos, da formalização de todas as atividades econômicas e da ampliação da capacidade de arrecadação, assim como do combate à sonegação. Assim, a coligação separa claramente a previdência como um sistema de proteção social negando sua caracterização como apenas um problema orçamentário comum que deve ser resolvido com contenção de gastos que futuramente levariam à retomada do crescimento econômico. 


\begin{tabular}{|c|c|c|c|}
\hline Coligação & $\begin{array}{c}\text { № páginas do } \\
\text { programa }\end{array}$ & Qual o problema da previdência & $\begin{array}{c}\text { Onde se encontra no } \\
\text { programa }\end{array}$ \\
\hline Novo & 23 & $\begin{array}{l}\text { - Injustiça na previdência: } \\
\text { trabalhadores do setor } \\
\text { público x privado } \\
\text { - Insustentabilidade da } \\
\text { previdência }\end{array}$ & $\begin{array}{l}\text { Previdência Justa e } \\
\text { Sustentável }\end{array}$ \\
\hline Essa é a solução - MDB/PHS & 21 & $\begin{array}{l}\text { - Injustiça na previdência: } \\
\text { público x privado }\end{array}$ & $\begin{array}{c}\text { Crescimento econômico } \\
\text { sustentado }\end{array}$ \\
\hline $\begin{array}{c}\text { Para Unir o Brasil - } \\
\text { PSDB, PP, PTB, PSD, } \\
\text { PRB, PR, DEM, SD e PPS }\end{array}$ & 15 & $\begin{array}{l}\text { - Injustiça na previdência: } \\
\text { público x privado }\end{array}$ & Brasil da Indignação \\
\hline $\begin{array}{l}\text { Mudança de Verdade - } \\
\text { Podemos, PSC, PRP, PTC }\end{array}$ & 15 & $\begin{array}{l}\text { - Não capitalização da } \\
\text { previdência }\end{array}$ & $\begin{array}{c}\text { Economia: capital para a } \\
\text { previdência }\end{array}$ \\
\hline $\begin{array}{l}\text { Brasil Acima de Tudo, Deus } \\
\text { Acima de Todos - } \\
\text { PSL e PRTB }\end{array}$ & 81 & - Ineficiência e corrupção & $\begin{array}{c}\text { Economia: garantia da } \\
\text { estabilidade } \\
\text { macroeconômica }\end{array}$ \\
\hline $\begin{array}{c}\text { Unidos para transformar o } \\
\text { Brasil -- REDE/PV }\end{array}$ & 43 & $\begin{array}{ll}\text { - } & \text { Gastos excessivos } \\
\text { - } & \text { Relação entre jovens/idosos } \\
\text { - } & \text { Regressividade da } \\
& \text { previdência }\end{array}$ & $\begin{array}{l}\text { Reformas que garantem } \\
\text { estabilidade econômica }\end{array}$ \\
\hline $\begin{array}{l}\text { Brasil Soberano - } \\
\text { PDT e AVANTE }\end{array}$ & 62 & $\begin{array}{l}\text { - Insustentabilidade fiscal da } \\
\text { previdência }\end{array}$ & Geração de empregos \\
\hline $\begin{array}{l}\text { O Povo Feliz de Novo - } \\
\text { PT, PCdoB e PROS }\end{array}$ & 61 & $\begin{array}{l}\text { - A previdência não apresenta } \\
\text { problemas }\end{array}$ & $\begin{array}{c}\text { Recuperação da } \\
\text { soberania popular }\end{array}$ \\
\hline $\begin{array}{c}\text { Vamos Sem Medo de Mudar o } \\
\text { Brasil-PSOL e PCB }\end{array}$ & 228 & $\begin{array}{ll}\text { - } & \text { A capitalização já ocorre } \\
\text { - } & \text { Desonerações e } \\
\text { desvinculações nas } \\
\text { contribuições sociais } \\
\text { - } & \text { Abandono da solidariedade } \\
\text { - } & \text { Financeirização da } \\
& \text { previdência complementar }\end{array}$ & $\begin{array}{c}\text { Previdência social: } \\
\text { nenhum direito a menos }\end{array}$ \\
\hline
\end{tabular}

Quadro 2: Resumo das posições sobre a previdência nas eleições 2018.

Fonte: Elaboração própria utilizando os programas de governo de cada coligação. 
A coligação "Vamos mudar sem medo" apresentou um programa que defendia mudanças na previdência com o intuito de aprofundar o sistema de solidariedade, rechaçando por completo o modelo de capitalização individualizado de previdência. Esta foi a única coligação a colocar a previdência como um fator dentro de um sistema de proteção social e welfare mais amplos. A coligação defendeu a unificação progressiva de todos os regimes previdenciários (RGPS e RPPS) em um mesmo sistema público de aposentadorias integrais, a garantia e ampliação do Orçamento da Seguridade Social com tributos ou percentuais vinculados e destinados as políticas que a compõem constitucionalmente, além do fim da contribuição dos aposentados e do fator previdenciário. Apesar disso tudo, as mudanças propostas pela coligação do PSOL e PCB não miraram nos novos riscos sociais, estando mais perto de ser uma regressão ao modelo originário da previdência pensada em 1988 do que uma atualização institucional com objetivo de combater os dilemas do EBES contemporâneo.

A maior parte das coligações explorou o problema da previdência como uma questão de injustiça e insustentabilidade. A narrativa padrão encontrada na maioria dos programas foi de que funcionários públicos são privilegiados pelo sistema em comparação aos trabalhadores do regime geral. Além disso, a previdência é posta como insustentável e um peso para a economia do país, se tornando uma razão para a atual crise econômica brasileira. Cabe destacar aqui que a questão demográfica aparece de forma clara apenas no programa da coligação Rede/PV.

A narrativa da injustiça da previdência ficou escancarada no programa da maior coligação da eleição. A coligação "Para unir o Brasil” do PSDB colocou a previdência como um motivo de indignação do povo brasileiro. Mais do que isso, o programa que está dividido em 3 seções conta como uma seção apenas para a solidariedade apostando em políticas de educação e saúde, porém deixando a previdência de fora (isto é, a previdência não como uma questão de solidariedade, mas sim de indignação).

Ficou evidente em todos os programas reformistas que a previdência não é um problema de solidariedade e proteção social. Sua questão foi tratada como um aspecto da economia formal onde ela assumiu um papel de obstáculo para o crescimento econômico, a retomada dos empregos e a estabilidade macroeconômica fiscal. 
O uso de símbolos, números e indicadores foi bastante restrito ao discutir a previdência e se limitaram a caracterizar o ambiente econômico, principalmente da questão empregatícia. Dados demográficos pouco apareceram, sendo utilizados apenas pela coligação Rede/PV. Uma caracterização numérica dos privilégios dos regimes especiais foi apresentada pela coligação MDB/PHS e pelo partido Novo. A coligação vencedora da eleição, PSL/PRTB não apresentou nenhum problema concreto, já assumindo uma solução.

De fato, como colocado por Zittoun (2014), o problema da previdência vinha acoplado das soluções desejáveis pelas coligações. A disputa pela representação do problema estava associada automaticamente com sua solução.

As soluções mais frequentes nos programas foram: a modificação da idade mínima; algum tipo de convergência entre os regimes especiais e o geral; e algum nível de capitalização individual que se sobrepõe ao modelo de repartição e solidariedade.

\begin{tabular}{|c|c|c|c|}
\hline \multicolumn{1}{|c|}{ Questões } & Idade Mínima & Convergência de regimes & Capitalização \\
\hline Rede/PV & $\mathrm{X}$ & $\mathrm{X}$ & $\mathrm{X}$ \\
\hline PDT/Avante & $\mathrm{X}$ & $\mathrm{X}$ & \\
\hline MDB/PHS & $\mathrm{X}$ & $\mathrm{X}$ & $\mathrm{X}$ \\
\hline Novo & $\mathrm{X}$ & & $\mathrm{X}$ \\
\hline Podemos, PSC, PRP, PTC & & & \\
\hline PSL /PRTB & & $\mathrm{X}$ & \\
\hline PSDB, PP, PTB, PSD, & & & \\
\hline PRB, PR, DEM, SD e PPS & & & \\
\hline
\end{tabular}

Quadro 3: Resumo das soluções para a questão da previdência nos 7 programas reformistas.

Fonte: Elaboração própria utilizando os programas de governo de cada coligação.

Falando de enquadramentos especificamente, observou-se uma disputa entre as coalizões da dualização (PT e PSOL) e da desregulação (os outros 7 programas). A discussão se centrou não na disputa por modelos de solidariedade, mas sim na criação de elos entre regras previdenciárias e geração de empregos e crescimento econômico. 
Para as coalizões da dualização a previdência como tal não apresenta obstáculos para o orçamento nacional e para o desenvolvimento do país, afinal com as mesmas regras previdenciárias o país viveu anos de crescimento econômico e chegou a números recordes de emprego e atividade econômica. Em específico, para o PSOL todas as camadas institucionais adicionadas desde a promulgação da constituição de 1988, como a EC 20 e a EC 41, deveriam ser revertidas.

No enquadramento dos 7 programas reformistas, vemos a previdência como um grande obstáculo para empregadores além de um peso desproporcional que vincula receitas do Estado não o permitindo investir em outras áreas. Ao utilizar o símbolo do privilégio, o enquadramento reformista escolheu os inimigos, a burocracia estatal e os regimes especiais, e as vítimas, os empresários que querem aumentar a oferta de emprego e não conseguem. Assim, a idade mínima é um remédio que permite cortar privilégios de pessoas que aposentam cedo e permite um desafogo para o orçamento futuro. A convergência entre regimes apareceu mais fortemente naqueles programas que utilizam o símbolo do privilégio estatal. Finalmente, a capitalização parcial apareceu nos programas ditos de "centro-esquerda" enquanto uma proposta de capitalização total fez parte dos programas das coligações da nova direita. A capitalização, para seus defensores, é uma solução que favorece tanto os empregadores como também oferece uma saída para as dificuldades orçamentárias impostas pelo pagamento da seguridade social.

\section{CONCLUSÃO}

Dilemas do bem-estar nas sociedades contemporâneas ou um problema fiscal pontual? Uma reforma onde não há alternativas ou múltiplas possibilidades de ajuste incluindo a possibilidade de rejeição total da reforma?

O trabalho proposto visa explorar estas perguntas que são o componente político de uma reforma que tem ganhado uma roupagem técnica e fatalista como se fosse inescapável. Assim, espera-se colocar em destaque os principais enquadramentos da proposta de reforma da previdência para ajudar na compreensão da formação dela.

Este trabalho não procurou fazer nenhum tipo de correlação entre vitória eleitoral e propostas previdenciárias. Tampouco procurou explicar qualquer tipo de 
resultado regional ou entre classes a partir das propostas para a previdência. De fato, a eleição não poderia ser resumida a apenas uma questão específica.

O que se mostrou foi o manejo de uma questão central para o EBES contemporâneo visto todos os novos riscos sociais associados aos problemas da previdência, da proteção social e do emprego formal e informal.

Como exposto, os partidos transformaram a questão da previdência não em uma discussão desse manejo dos novos dilemas, mas sim em uma válvula de escape para a crise econômica e política ampla (e moral, visto que um dos alvos-símbolo foi o privilégio de uma elite). Assim, o afrouxamento das leis empregatícias, incluindo a previdência, gerariam mais empregos. Ademais, o excedente orçamentário poderia ser usado "no que realmente importa".

Concluindo, o trabalho visou demonstrar que a crise econômica foi utilizada como um importante fator para discutir direitos e instituições que perdurarão no tempo e que não deveriam ser tratada como remédio imediato para problemas que são muito maiores do que ela.

\section{REFERÊNCIAS}

Banting, Keith e Myles, John. Framing the New Inequality: The Politics of Income Redistribution in Canada. In: Green, David et al. Income Inequality: The Canadian Story. Institute for Research in Public Policy, 2016, pp. 509-540.

Baumgartner, Frank e Jones, Bryan. Agendas and Instability in American Politics. The University of Chicago Press, Second Edition, [1993] 2009.

Birkland, Thomas. Agenda Setting in Public Policy. In: Fischer, F., Miller, G., Sidney, M. Handbook of Public Analysis: Theory, Politics and Methods, Boca Raton: CRC Press, 2007, pp. 63-78.

Bonoli, Giuliano. New social risks and the politics of post-industrial social policies. In: Armingeon, Klaus e Bonoli, Giuliano (ORG.). The Politics of Post-Industrial Welfare States Adapting post-war social policies to new social risks, New York: Routledge, 2006, pp. 3-26.

Boschi, Renato e Pinto, Carlos Eduardo Santos. Crisis and Austerity: the recent trajectory of capitalist development in Brazil . Contemporary Politics, v. 25:3, pp. 292312, 2019.

Collier, Ruth e Collier, David. Shaping the Political Arena: Critical Junctures, the Labor Movement, and Regime Dynamics in Latin America. University of Notre Dame Press, Second Edition [1991] 2002.

Esping-Andersen, Gotha. The Three Worlds of Welfare Capitalism. Princeton University, third edition, 1993. 
Haas, Peter. Epistemic Communities and International Policy Coordination. International Organization, Vol 46, no 1, 1992, pp. 1-35.

IBGE, Pesquisa nacional por amostra de domicílio contínua - PNAD CONTÍNUA: Principais destaques da evolução do mercado de trabalho no Brasil, 2019.

Kerstenetzky, Célia. O Estado de Bem-Estar Social na Idade da Razão, a reinvenção do Estado Social no mundo contemporâneo. Rio de Janeiro: Elsevier Editora, 2012.

Kingdom, John. Agendas, Alternatives, and Public Policy. Pearson Education Limited, Second Edition, [1984] 2014.

Marques, Rosa Maria; Mendes, Áquila; Guino, Camila; Andrade, Patrick. A Previdência Social: da Constituição à reforma de Lula, Revista Textos e Contextos, Vol. 8, № 2, 2009, pp. 195-218.

Pierson, Paul. Increasing Returns, Path Dependence, and the Study of Politics. American Political Science Review, Vol. 94, no2, 2000, pp. 251-267.

Prates, Daniela M.; Fritz, Barbara; de Paula, Luiz Fernando. O desenvolvimentismo pode ser culpado pela crise? Uma classificação das políticas econômica e social dos governos do PT ao governo Temer. IE-UFRJ: Texto para Discussão 009, 2019.

Piketty, Thomas. Capital in Twenty-First Century. The Belknap Press of Harvard University Press, 2014.

Rochefort, David e Cobb, Roger. Problem Definition: An Emerging Perspective. In: Rochefort, David e Cobb, Roger, The Politics of Problem Definition: Shaping the Policy Agenda, University Press of Kansas, 1994, pp. 1-27.

Rothstein, Bo; Samanni, Marcus; Teorell, Jan. Explaining the welfare state: power resources vs. the Quality of Government, European Political Science Review, v.4:1, 2012, pp.1-28.

Serrano, Franklin e Summa, Ricardo. Demanda agregada e a desaceleração do crescimento econômico brasileiro de 2011 a 2014. Center for Economic and Policy Research, 2015.

Skocpol, Theda. Bringing the state back in: Strategies of analysis in current research. In: Evans, Peter; Rueschemeyer, Dietrich; Skocpol, Theda (ORG.). Bringing the state back in, Cambridge University Press, 1985, pp.3-37.

Stone, Deborah. Policy Paradox: The Art of Political Decision Making. W.W. Norton \& Company, Third Edition, [1988] 2012.

Streeck, Wolfgang e Thelen, Kathleen. Introduction: Institutional Change in Advanced Political Economies. In; Streeck, W. \& Thelen, K (ORG.). Beyond Continuity: Institutional Change in Advanced Political Economies, Oxford University Press, 2005, pp. 1-39.

Thelen, Kathleen. Varieties of Liberalization and the New Politics of Social Solidarity. Cambridge University Press, 2014.

Wildavsky, Aaron. The Art and Craft of Policy Analysis. Palgrave Macmillan, [1979] 2018.

Zahariadis, Nikolaos. Setting the agenda on agenda setting: definitions, concepts, and controversies. In: Zahariadis, Nikolaos (ORG.). Handbook of Public Policy Agenda Setting, Edward Elgar Publishing, 2016, pp. 1-22.

Zittoun, Philippe. The Political Process of Policymaking: A Pragmatic Approach to Public Policy. Palgrave Macmillan, 2014. 